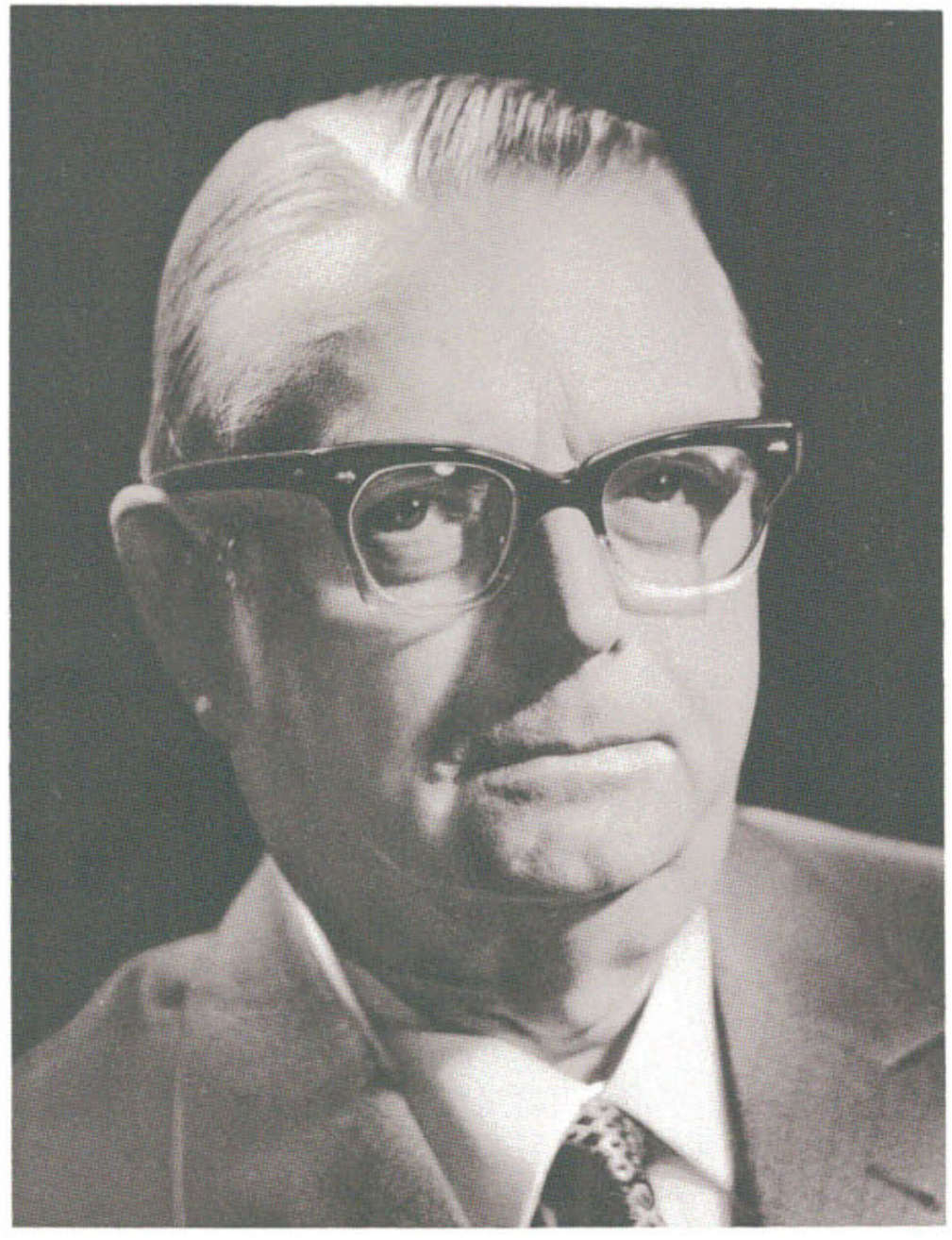





\section{GRUSSWORT AN DEN JUBILAR}

Freunde, Kollegen und Schüler, und die Herausgeber der „Zeitschrift“ bringen Ihnen, lieber Herr Wolf, diesen Band der alten ÄZ zur Vollendung Ihres siebenten Jahrzehnts mit herzlichen Wünschen dar. Sie gedenken dabei nicht zuletzt des Herausgebers der „Zeitschrift“ in den Jahren 1935-1943. Wir Ägyptologen sind noch immer in der glücklichen Lage, eine überschaubare Familie zu bilden. So können wir unseren Jubilaren Gaben darbringen, die zugleich persönlichen und sachlichen Anłiegen dienen. Wir wissen, was der Einzelne kraft seiner Eigenheit zum ganzen Bau beigetragen hat. Daher werden Sie hier vieles finden, das - ausdrücklich oder nicht - auf Thre Arbeiten Bezug nimmt und somit auf dem Wege über das „Individuum“ zur ägyptologischen „Gemeinschaft" führt. Sie werden Arbeiten zur ägyptischen Kunst antreffen, die mehr und mehr zu Threm wissenschaftlichen Zentrum geworden ist. Darüber hinaus haben die hier versammelten Autoren von Threm Erstling „Amenophis IV.“ bis zu Ihrer beizeiten formulierten Sorge, daß „die Ägyptologie als historische Wissenschaft" verstanden werden möge, Begegnungen vollzogen, auf die der diensthabende $\underline{H} r w$ hbt Sie unter allen Lesern am wenigsten aufmerksam zu machen braucht.

Als gebürtiger Hildesheimer, der in dieser traditionsmächtigen Stadt das humanistische Gymnasium absolvierte, stand Ihnen der Zugang zur Ägyptologie frühzeitig offen. Er führte über die Denkmäler, die das 1911 eröffnete Pelizaeus-Museum bereithielt. Ja, man möchte die Vermutung wagen, daß die beispielhaften und bis zum Glanz des Hemon hinaufreichenden Schätze aus dem Alten Reich Thnen noch vor dem bewußten Studium der Dinge den Schlüssel zum Wesen der ägyptischen Kunst eingehändigt haben, das Sie mit so entschiedenem Vorrang von den Werken dieser frühen Phase her aufzuschließen suchen. Ihr erster akademischer Lehrer in Aegyptiacis wurde H. Ranke, nachdem Sie sich 1919 in Heidelberg als Student der Ägyptologie, der Semitischen Sprachen und Klassischen Archäologie einschreiben ließen. 1921 gingen Sie zu Sethe nach Göttingen, um ägyptische Philologie strengster Observanz kennenzulernen. Das Jahr darauf führte Ihr Weg nach Berlin, wo Sie bald auch als wissenschaftlicher Hilfsarbeiter am Museum tätig geworden sind. Ihr Respekt vor Erman und Sethe war dauerhaft. Dazu haben Sie sich eine besondere Neigung für H. Schäfer bewahrt, die ihren letzten Ausdruck in dem warmherzigen Nachruf auf den Altmeister ägyptischer Kunstforschung in unserer Zeitschrift fand. Im Sommer 1923 promovierten Sie in Heidelberg bei Ranke mit einer Arbeit über Amenophis IV. Eine fruchtbare Dienstzeit als Referent am Kairener Institut (1926/27) begründete Ihre ausgezeichnete Landeskunde Ägyptens. Nach erneuter Mitarbeit am Berliner Museum (1927/28) habilitierten Sie sich in Leipzig bei Steindorff mit einer wertbeständigen Untersuchung über das Schöne Fest von Opet. Hier wurden Sie 1934 planmäßiger ao., 1939 o. Professor und schickten sich an, diese reizvolle Stätte ägyptologischer Forschung mit guter Bibliothek und profilierter Sammlung zu einem neuen Zentrum auszubauen. Durch Kriegsdienst und Gefangenschaft wurden Sie aber von 1939 bis 1946 aus der Arbeit gerissen, doch war es Ihnen noch möglich, die Bibliothek und die Bestände des Museums in Leipzig rechtzeitig bergen zu lassen und vor der Zerstörung zu bewahren, der die alten Räume vollständig anheimfielen. Nach dem Kriege bauten Sie der Ägyptologie in Münster eine Stätte auf, wo Sie seit 1949 als Gastprofessor und von 1959 bis zu Threr Emeritierung als o. Professor insgesamt etwa zwanzig Jahre gewirkt haben.

Vieles von dem, was Sie gewollt und zu einem guten Teil auch erreicht haben, trägt dazu bei, die Ägyptologie aus einer Isolierung zu lösen. Die von Ihnen vollzogene Integration ägyptologischer Archäologie in die allgemeine Kunstwissenschaft liegt auf der Linie von Forschungen, in dem die 
Universitas litterarum ihre Lebenskraft zeigen wird. Die geistige und nicht selten auch physische Energie, die Sie in eine rechtverstandene Popularisierung unserer Wissenschaft gesteckt haben, hat im persönlichen Bereich der Ägyptologie viele Freunde gewonnen. Dauerhaft und sachlich aber hat sie dank Threr fundierten Darstellungen ägyptischer Geschichte und Kultur in guter und klarer Sprache Wege zur Verständigung zwischen den Fächern geöffnet, für die die herkömmliche Isolierung auf die Länge der Zeit einer Selbstverstümmelung gleichgekommen wäre. Schließlich war Thre offen ausgesprochene Warnung vor einem Anhäufen von Materialien um seiner selbst willen nur zu berechtigt. Jedenfalls hat die jüngere Generation längst zu lernen begonnen, daß das Nachdenken über die Dinge genau so wichtig ist wie ihre Sammlung und daß auch mit neuen Methoden neue Erkenntnisse zu gewinnen sind, vor allem, wenn neuer Stoff nicht zu erwarten steht. Wer bei Thnen studiert hat, konnte nicht mißverstehen, wie Sie es meinten: Sammeln ist selbstverständlich, aber es ist nicht Selbstzweck. Denn der Ägyptologe soll in unseren Jahrzehnten nicht zum Antiquar, sondern zum Historiker erzogen werden.

Doch Thre Modernität schließt auch praktische Dinge ein. Wer Sie seit langem als leidenschaftlichen und meisterhaften Autofahrer kennt, wird sich kaum wundern zu hören, daß Sie als kaum Achtzehnjähriger auf dem Wege gewesen waren, Marineoffizier zu werden. Dahinter stand freilich etwas anderes und Tieferes als die Technik. Es ist die Liebe zum Meer und zur Weite, die Sie nach der Emeritierung schließlich bestimmt hat, Thren Wohnsitz in Hamburg zu nehmen. Möge Thnen dort noch viel gelehrte und humane Einsicht beschieden sein durch den Blick auf die Ferne der See und in die Tiefen der Geschichte jener alten Hochkultur, in deren Dienst wir alle mit Thnen verbunden sind. 